\title{
HPV-Low Risk
}

National Cancer Institute

\section{Source}

National Cancer Institute. HPV-Low Risk. NCI Thesaurus. Code C157254.

Any of a number of strains of human papillomavirus (HPV) that cause genital warts in humans and are rarely associated with carcinogenesis. 